\title{
In-vivo evaluation of a reinforced ovine biologic: a comparative study to available hernia mesh repair materials
}

\author{
N. Overbeck ${ }^{1}$ - G. M. Nagvajara' ${ }^{1}$ S. Ferzoco ${ }^{2}$ B. C. H. May ${ }^{3}$ A. Beierschmitt ${ }^{4} \cdot$ S. Qi ${ }^{5}$
}

Received: 17 September 2019 / Accepted: 30 December 2019 / Published online: 31 January 2020

(c) The Author(s) 2020

\begin{abstract}
Purpose Two innovative reinforced biologic materials were studied in a non-human primate hernia repair model. The test articles, which combine layers of ovine decellularized extracellular matrix with minimal amounts of synthetic polymer, were evaluated for their biologic performance as measured by inflammatory response, healing kinetics, integration, and remodeling into functional host tissue. For comparison, seven clinically used biologic and synthetic meshes were also studied.

Methods Animals were implanted with test articles in surgically created full-thickness midline abdominal wall defects, and evaluated macroscopically and histologically at 4,12 , and 24 weeks.

Results Macroscopically, biologics resorbed and remodeled into naturally appearing tissue; the reinforced biologics appeared similar, but remodeled earlier and were less prone to stretch. Synthetics developed a layer of reactive tissue above and separate from the contracted mesh structure. At early time points, the collagen networks of biologics and reinforced biologics were infiltrated by host cells primarily as a peripheral layer on the biologics. As early as 12 weeks, the collagen networks associated with the reinforced biologics remodeled into organized host collagen. By 24 weeks, both reinforced biologics and biologics had low levels of inflammation. In contrast, a foreign body response persisted at 24 weeks with the synthetics, which had developed less organized collagen, separate in space from the actual mesh.

Conclusions The current study shows a favorable response to reinforced biologics, which were associated with an initial inflammatory response, resolving by later time points, followed by active remodeling, and the formation of new morphologically functional collagen.
\end{abstract}

Keywords Hernia repair $\cdot$ Mesh repair materials $\cdot$ Biologic $\cdot$ Synthetic $\cdot$ Decellularized extracellular matrix

\section{Introduction}

Hernia repairs represent one of the most common surgical procedures performed. The introduction of reinforcement of incisional or ventral hernia repair with synthetic meshes

\footnotetext{
Electronic supplementary material The online version of this article (https://doi.org/10.1007/s10029-019-02119-z) contains supplementary material, which is available to authorized users.

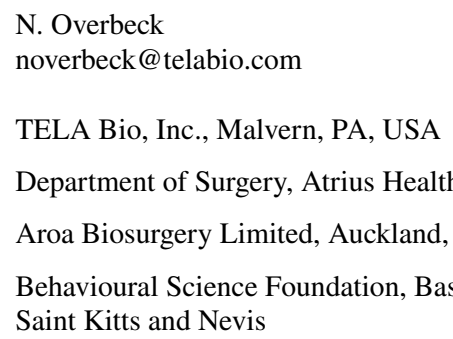

has significantly reduced the risk of recurrence, i.e., postoperative failure of the hernia repair. Despite that, recurrence remains a common problem. A landmark randomized prospective study found a 10-year cumulative incidence of recurrence of $63 \%$ for suture repairs and $32 \%$ for mesh reinforced suture repairs [1]. However, data from the Danish registry study showed that the benefits of synthetic mesh reinforced repairs diminish over time, as on average about $1 \%$ of patients each year undergo an additional surgical procedure for mesh related complications [2].

Traditional meshes have typically been classified into three broad classes: permanent synthetics, resorbable synthetics, and biologics. The most widely used meshes are permanent synthetics; made either from polypropylene (PP), polytetrafluoroethylene (PTFE), or polyester. Although these materials are strong and affordable, their usage is associated with dose-dependent chronic inflammation, scar formation, migration, and nerve entrapment [3]. Additionally, these 
meshes become brittle and contract over time, and are difficult and destructive to remove [4]. Resorbable synthetics, made either of combinations of polyglycolic acid (PGA), polylactic acid (PLA), and trimethylene carbonate (TMC), or poly-4-hydroxybutyrate (P4HB) have similar attributes to permanent synthetic meshes once implanted but have a relatively short clinical history. As such, there are limited data on recurrence rates after the implants are fully resorbed. In one such study, implants made from 67\% PGA and 33\% TMC that resorbed in 6 months had a $17 \%$ recurrence rate at 2 years [5]. A prospective multicenter study for P4HB reported 19 recurrences in 82 patients, or 23\%, at 3 years [6].

Biologic materials have gained favor for repair of hernias in infected or contaminated fields and other high-risk patients [7]. Biologics are produced from mammalian (e.g., human, ovine, bovine, or porcine) source tissues that undergo processes to remove the cellular components, leaving an intact and functional tissue extracellular matrix $(\mathrm{ECM})$. ECMs that are properly decellularized (dECM) retain signaling and adhesion molecules that promote the proliferation of fibroblasts, deposition of collagen, and the development of new blood vessels, and provide a threedimensional scaffold for the growth and remodeling into native tissue at the defect site $[8,9]$.

Although biologics provide support and a scaffold for tissue-specific cell growth, signaling, and remodeling, they are expensive, and, more importantly, clinical evidence shows the remodeled tissue may stretch over time [10, 11]. Furthermore, the very fact that biologics are derived from different human or animal tissues, such as dermis, small intestinal or bladder submucosa, and pericardium - contributes to significant differences in performance. This is further compounded by differences in the decellularization processes used and other manufacturing steps [12]. Based on the characteristics and clinical results described, there clearly is room for improvement in hernia repair materials.

An improved surgical mesh material for soft-tissue reconstruction would combine desirable features of both biologic and synthetic materials resulting in a reduction and attenuation of the inflammatory effect of the implant, resistance to infection, rapid remodeling into functional tissue, and the prevention of overextension and laxity.

Reinforced biologics were developed to provide such an improved construct. The reinforced biologics combine the adventitious properties of biologics and synthetics, and consist of layers of intact and functional dECM, namely ovine forestomach matrix (OFM), embroidered together with minimal amounts of synthetic polymer to specifically reinforce the construct. They have been used clinically since July 2016, and at the time of this writing, they have been implanted in over 7000 patients. The biological response and integration following implantation of the reinforced biologics was evaluated in a non-human primate model and directly compared to clinically used synthetic and biologic devices. The objective of the study was to evaluate the overall healing of the defect as evidenced by the cellular response, and the morphological appearance of the tissue associated with each implant. Although this model had some limitations in terms of mimicking the clinical aspects of the condition and its repair, it served to provide comparative and relevant data in a large animal model through a 24 -week period of time.

\section{Materials and methods}

\section{Test articles}

Nine test articles were evaluated in this study, including the two novel reinforced biologics, OviTex $1 \mathrm{~S}^{\circledR}$ Resorbable and OviTex $1 \mathrm{~S}^{\circledR}$ Permanent (designed by TELA Bio, Malvern, PA, USA), as well as Phasix ${ }^{\mathrm{TM}}$ (C.R. Bard, Inc./Davol, Inc., Warwick, RI, USA), Ventralight ST ${ }^{\mathrm{TM}}$ (C.R. Bard, Inc./ Davol, Inc., Warwick, RI, USA), Physiomesh ${ }^{\mathrm{TM}}$ (Ethicon, Inc., Somerville, NJ, USA), Strattice ${ }^{\mathrm{TM}}$ Firm [LifeCell Corporation, Branchburg, NJ, USA (now Allergan)], SurgiMend $1.0^{\circledR}$ (Integra LifeSciences Corp., Plainsboro, NJ, USA), Gentrix ${ }^{\circledR}$ Surgical Matrix Plus (ACell Inc., Columbia, Maryland), and Zenapro ${ }^{\circledR}$ (Cook Medical, West Lafayette, IN, USA) (Table 1). Materials were prepared according to their respective IFUs.

\section{Reinforced biologics}

Reinforced biologics were prepared from layers of ovine forestomach matrix (OFM) produced from ovine (sheep) forestomach using proprietary decellularization methods (Aroa Biosurgery, New Zealand). OviTex $1 S^{\circledR}$ Resorbable and OviTex $1 S^{\circledR}$ Permanent were created from layers of OFM, using either polypropylene (PP) or polyglycolic acid (PGA) suture (2-0). All devices were terminally sterilized (ethylene oxide) prior to use in the study. Implants used in this study consisted of six layers-four layers of OFM, embroidered with a 6-mm grid pattern, and two additional OFM layers to prevent intestinal adhesion on one side using a 25-mm grid design.

\section{Surgical procedure}

Seventy-three (73) adult vervet monkeys (Cercopithecus aethiops) (3-6 kg) obtained through the Behavioural Science Foundation (BSF), St. Kitts were used in this study. The protocol for this study was reviewed and approved by the BSF Institutional Animal Care and Use Committee (IACUC). BSF holds a certificate of Good Animal Practice with the Canadian Council on Animal Care (CCAC) and observes Guidelines for the Care and Use of Laboratory 
Table 1 Test articles, mesh classification, source materials, and explant time points

\begin{tabular}{|c|c|c|c|c|c|}
\hline Mesh & Manufacturer & Class & Composition & Time point (weeks) & $\begin{array}{l}\text { Animals per } \\
\text { time point }\end{array}$ \\
\hline OviTex ${ }^{\circledR}$ PGA 1S & $\begin{array}{l}\text { Developed, designed and manu- } \\
\text { factured by: Aroa Biosurgery } \\
\text { Limited and TELA Bio, Inc }\end{array}$ & Reinforced biologic & $\begin{array}{l}\text { Decellularized ovine forestom- } \\
\text { ach matrix ECM embroidered } \\
\text { with polyglycolic acid (PGA) }\end{array}$ & $4,12,24$ & 3 \\
\hline OviTex ${ }^{\circledR}$ PP 1S & & Reinforced biologic & $\begin{array}{l}\text { Decellularized ovine forestom- } \\
\text { ach matrix ECM embroidered } \\
\text { with polypropylene (PP) }\end{array}$ & $4,12,24$ & 3 \\
\hline Phasix $^{\mathrm{TM}}$ & CR Bard (Davol) & Resorbable synthetic & $\begin{array}{l}\text { Poly-4-hydroxybutyrate (P4HB) } \\
\text { and polyglycolic acid (PGA) }\end{array}$ & $4,12,24$ & 3 \\
\hline Ventralight ST ${ }^{\mathrm{TM}}$ & CR Bard (Davol) & Permanent synthetic & $\begin{array}{l}\text { Polypropylene and polyglycolic } \\
\text { acid (PGA) with sodium } \\
\text { hyaluronate (HA) carboxy- } \\
\text { methylcellulose (CMC) and } \\
\text { polyethylene glycol (PEG) } \\
\text { based hydrogel barrier }\end{array}$ & $4,12,24$ & 3 \\
\hline Physiomesh ${ }^{\mathrm{TM}}{ }^{\mathrm{a}}$ & Ethicon & Permanent synthetic & $\begin{array}{l}\text { Polypropylene laminated } \\
\text { between polyglecaprone- } 25 \\
\text { films bond w/polydioxanone } \\
\text { film }\end{array}$ & $4,12,24$ & 2 \\
\hline Strattice ${ }^{\mathrm{TM}}$ Firm & LifeCell (now Allergan) & Biologic & $\begin{array}{l}\text { Decellularized porcine dermal } \\
\text { ECM }\end{array}$ & $4,12,24$ & 5 \\
\hline SurgiMend $1.0^{\mathrm{TM}}$ & TEI Biosciences (now Integra) & Biologic & $\begin{array}{l}\text { Decellularized fetal bovine } \\
\text { dermal ECM }\end{array}$ & 4,12 weeks & 3 \\
\hline $\begin{array}{l}\text { Gentrix }^{\circledR} \text { Surgi- } \\
\text { cal Matrix Plus }\end{array}$ & ACell & Biologic & $\begin{array}{l}\text { Decellularized porcine urinary } \\
\text { bladder ECM }\end{array}$ & 4,12 & 2 \\
\hline Zenapro $^{\mathrm{TM}}{ }^{\mathrm{a}}$ & Cook Medical & Hybrid biologic & $\begin{array}{l}\text { Decellularized porcine small } \\
\text { intestinal submucosa ECM } \\
\text { and polypropylene }\end{array}$ & 4,12 & 3 \\
\hline Total animals & & & & & 73 \\
\hline
\end{tabular}

${ }^{\mathrm{a} N o}$ longer in distribution

Animals (as outlined in NIH Publication \#85-23 Rev. 1985). Animal screening and handling, as well as full-thickness $7 \times 3-\mathrm{cm}$ abdominal wall defect creation, implant sample inlay ("bridging") repair, and post-surgical treatment procedures were performed as described in the literature [13, 14]. Study details are presented in Table 1.

The monkeys were screened for general health and quarantined for a minimum of 32 days prior to study entry. Two weeks or less, prior to study commencement, the animals were given complete physicals, observed for good health, and then moved to single-cage stainless steel housing where they can see other conspecifics and receive daily enrichment to encourage normal species-specific behaviors. The animals remained in this housing throughout the study to prevent normal cage mate behaviors from possibly damaging the implant site.

An initial intramuscular injection of Ketamine $\mathrm{HCl}$ $(10 \mathrm{mg} / \mathrm{kg})$ was used to handle the animals and bring them to surgery where they were weighed and aseptically prepped, and an IV catheter was placed in the saphenous vein. A maintenance rate of Lactated Ringers is given throughout surgery. A surgical plane of anesthesia was maintained with xylazine and ketamine, given by intramuscular injection $(1: 10,10 \mathrm{mg} / \mathrm{kg})$. A pre-op dose of a broad-spectrum antibiotic was used.

A longitudinal mid-abdominal skin incision of approximately $7 \mathrm{~cm}$ was made to expose an area of the linea alba and muscle wall. Then, a $7 \times 3-\mathrm{cm}$ full-thickness "window" defect was created in the midline of the abdominal wall removing sections of both rectus muscles, including the fasciae and the peritoneum.

The abdominal wall defect was then repaired with an implant of the test sample equal in size to the defect (approximately $7 \times 3 \mathrm{~cm}$ ) using an inlay ('bridging') approach (see Table 1 for number of animals per group). The implant was anchored at each of the four corners with 2-0 non-absorbable polypropylene sutures in an interrupted pattern, and was sutured to the edges of the rectus abdominal muscle and fascia with non-absorbable 2-0 polypropylene running sutures.

The subcutaneous tissue was closed with an absorbable polydioxanone suture (2-0) in a running pattern. Finally, the skin was closed with non-absorbable nylon sutures (2-0) in an interrupted pattern. 
An intra operative dose of an opioid and an NSAID was given for analgesia and continued for a minimum of 3 days post op or as deemed necessary from pain scoring at observations.

Animal care technicians recorded clinical observations at least once daily for the duration of the study, and body weight was recorded at each physical examination. In addition, a daily pain scale was employed to ensure animals were provided adequate post-surgical pain relief and in the event of any painful procedure or event.

\section{Implant recovery}

Implants were recovered at 4, 12, and 24 weeks (Table 1), and evaluated by a veterinarian for signs of herniation, inflammation, adhesions, contraction, or other abnormalities as well as evidence of healing and integration as described in the literature $[13,15,16]$. Adhesion tenacity was scored on strength from zero to three, where $0=$ no adhesions, $1=$ adhesions easily freed with gentle tension, $2=$ adhesions freed with blunt dissection, and $3=$ adhesions requiring sharp dissection to be freed [10]. The length and width of the implant was measured in-situ for calculation of percent of the starting area $\left(21 \mathrm{~cm}^{2}\right)$ as well as aspect ratio (determined as the ratio of in-situ implant length to width). The entire implant and surrounding tissue were removed and photographed. A midline cross section of each implant was removed, cut in half, and placed in $10 \%$ neutral buffered formalin for histologic analysis.

\section{Histology and histopathology}

The formalin fixed specimens were embedded in paraffin, cut into sections, and stained with hematoxylin and eosin (Tejas Pathology Associates, Tomball, TX, USA). Two slides were prepared from each animal: left and right host-implant interface. The slides were evaluated by a pathologist who was blind to treatment and time point (CBSET Inc, Lexington,
MA, USA). Established standard toxicological pathology criteria were used as a guide to create a scoring methodology categorizing the microscopic tissue appearance on a scale from 0 to 4 (Table 2). Values obtained from the histomorphology analysis were entered in Microsoft ${ }^{\circledR}$ Excel $^{\circledR}$, reported as the group median, mean $\pm \mathrm{SD}$, and percent incidence. Calculations, data organization, and graphs were generated using Minitab ${ }^{\circledR}$ software (Version 17). Inflammation was scored on the extent of inflammatory cells (macrophages, neutrophils, giant cells, lymphocytes, and plasma cells) within or associated with the test article. Pertinent microscopic observations were scored for intra- and periimplant cellular responses, implant presence, fibrosis/collagen organization, and vascularization. Abdominal wall defect-associated tissue was scored comparing the thickness of the defect area to the abutting abdominal tissue. Implantto-tissue ratio was quantified based on the amount of remaining implant material in relation to the total thickness of the tissue inside the defect site.

\section{Results}

\section{Gross necropsy observations}

Representative images for each of the test samples at each time point are provided in Fig. 1.

There were no signs of herniations in any of the animals. However, the two Gentrix Surgical Matrix Plus implants at 4 weeks had torn away from approximately $75 \%$ and $50 \%$ of the defect perimeter, respectively, and those at 12 weeks could not be identified in the defect area (Supplementary Fig. 1). Based on this, Gentrix Surgical Matrix Plus was not included in any further analyses.

All animals showed surface adhesions of the omentum, which were freed with blunt dissection except for Phasix and Physiomesh, which required sharp dissection to remove at 24 weeks (Table 3 ).

Table 2 Histomorphology scoring matrix

\begin{tabular}{|c|c|c|c|c|}
\hline Score & Inflammation/inflammatory cells & Pertinent microscopic observations & Abdominal wall defect-associated tissue & $\begin{array}{l}\text { Implant- } \\
\text { to-tissue } \\
\text { ratio }\end{array}$ \\
\hline 0 & Absent & No response/not detectable & Absent & Absent \\
\hline 1 & $\begin{array}{l}\text { Rare, minimal 1-5/per high power field } \\
\text { (hpf; } 40 \times \text { obj) }\end{array}$ & Minimal/focal/barely detectable & Minimal (i.e., notably thinner) & $<25 \%$ \\
\hline 2 & Mild, 5-10/hpf & $\begin{array}{l}\text { Mild/focal or rare multifocal/slightly } \\
\text { detectable }\end{array}$ & Mild (i.e., slightly thinner) & $25-50 \%$ \\
\hline 3 & $\begin{array}{l}\text { Heavy infiltrate, with preservation of } \\
\text { local architecture }\end{array}$ & $\begin{array}{l}\text { Moderate/multifocal to confluent/easily } \\
\text { detectable }\end{array}$ & Moderate (i.e., equivalent in thickness) & $50-75 \%$ \\
\hline 4 & $\begin{array}{l}\text { Packed, with effacement of regional } \\
\text { architecture }\end{array}$ & Marked/diffuse/overwhelming presence & $\begin{array}{l}\text { Marked (i.e., thicker than the abdominal } \\
\text { wall) }\end{array}$ & $>75 \%$ \\
\hline
\end{tabular}




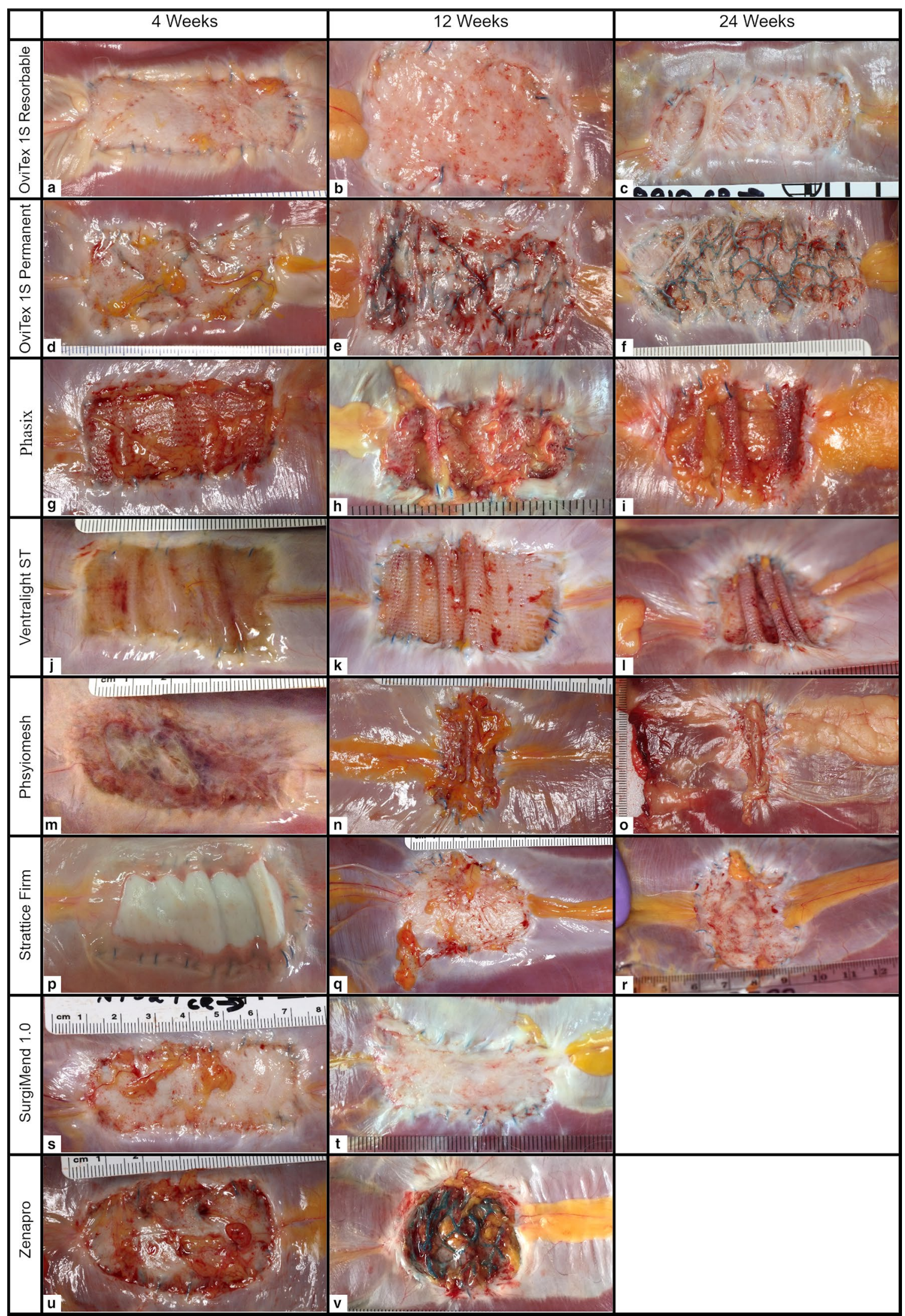

Fig. 1 Gross necropsy images of implants at 4, 12, and 24 weeks 
Table 3 Average in-situ length, width, area, percent of starting area, aspect ratio, and omentum adhesion strength

\begin{tabular}{|c|c|c|c|c|c|c|}
\hline Group & $\begin{array}{l}\text { In situ } \\
\text { length } \\
(\mathrm{cm})\end{array}$ & $\begin{array}{l}\text { In situ } \\
\text { width } \\
(\mathrm{cm})\end{array}$ & $\begin{array}{l}\text { In situ } \\
\text { area } \\
\left(\mathrm{cm}^{2}\right)\end{array}$ & $\begin{array}{l}\text { In situ percent } \\
\text { starting area }\end{array}$ & $\begin{array}{l}\text { In situ aspect } \\
\text { ratio }(\mathrm{L}: \mathrm{W})\end{array}$ & $\begin{array}{l}\text { Omentum } \\
\text { adhesion } \\
\text { strength }\end{array}$ \\
\hline \multicolumn{7}{|l|}{4 weeks } \\
\hline OviTex 1S Resorbable & 5.7 & 2.2 & 13.1 & 0.6 & 2.6 & 1.7 \\
\hline OviTex 1S Permanent & 5.1 & 2.7 & 13.7 & 0.7 & 1.9 & 2.3 \\
\hline Phasix & 5.0 & 2.5 & 12.4 & 0.6 & 2.0 & 2.0 \\
\hline Ventralight ST & 4.2 & 2.6 & 11.1 & 0.5 & 1.6 & 1.0 \\
\hline Physiomesh & 5.6 & 3.0 & 16.3 & 0.8 & 2.0 & 1.5 \\
\hline Strattice Firm & 4.9 & 2.9 & 14.2 & 0.7 & 1.7 & 2.0 \\
\hline SurgiMend 1.0 & 5.8 & 2.9 & 16.9 & 0.8 & 2.0 & 2.0 \\
\hline Zenapro & 5.2 & 2.7 & 14.2 & 0.7 & 2.0 & 2.0 \\
\hline \multicolumn{7}{|l|}{12 weeks } \\
\hline OviTex 1S Resorbable & 4.5 & 3.5 & 15.9 & 0.8 & 0.5 & 1.0 \\
\hline OviTex 1S Permanent & 4.1 & 3.0 & 12.2 & 0.6 & 0.5 & 1.7 \\
\hline Phasix & 4.2 & 2.7 & 11.1 & 0.5 & 0.6 & 2.0 \\
\hline Ventralight ST & 4.3 & 2.3 & 10.1 & 0.5 & 0.1 & 1.0 \\
\hline Physiomesh & 3.6 & 2.8 & 8.7 & 0.4 & 1.6 & 2.0 \\
\hline Strattice Firm & 4.3 & 3.4 & 13.9 & 0.7 & 0.8 & 2.0 \\
\hline SurgiMend 1.0 & 4.4 & 3.0 & 14.1 & 0.7 & 0.9 & 1.3 \\
\hline Zenapro & 4.0 & 3.1 & 12.2 & 0.6 & 0.0 & 2.0 \\
\hline \multicolumn{7}{|l|}{24 weeks } \\
\hline OviTex 1S Resorbable & 5.2 & 2.5 & 13.6 & 0.6 & 0.6 & 1.7 \\
\hline OviTex 1S Permanent & 6.7 & 2.4 & 16.3 & 0.8 & 0.7 & 2.0 \\
\hline Phasix & 4.3 & 2.8 & 11.4 & 0.5 & 0.9 & 3.0 \\
\hline Ventralight ST & 3.4 & 2.6 & 8.8 & 0.4 & 0.3 & 1.7 \\
\hline Physiomesh & 1.9 & 3.9 & 7.2 & 0.3 & 0.0 & 3.0 \\
\hline Strattice Firm & 4.5 & 5.4 & 23.2 & 1.1 & 1.0 & 1.4 \\
\hline SurgiMend 1.0 & - & - & - & - & - & - \\
\hline Zenapro & - & - & - & - & - & - \\
\hline
\end{tabular}

There was a wide variety of implant geometry at the various time points as the implants contracted or stretched to different degrees in length and width (Fig. 1). The geometry was analyzed by measuring the percent reduction in defect area, and the aspect ratio (measure of length over width) (Table 3). All implants at all time points showed a reduction in area (Table 3), except for Strattice Firm, which at 24 weeks had stretched to $110 \%$ of the original defect area. The most contracted implants were the synthetics, which had reduced to less than $50 \%$ of the defect area by 12 weeks and further reduced by 24 weeks, forming rolls in the mesh (Fig. 1i, 1, o). At 4 weeks, test articles essentially retained their aspect ratios (approx. 2.33). However, by 24-week differences between the test articles were observed. For example, at 24 weeks, the reinforced biologics best preserved the original aspect ratio of the defect area (2.45 average), whereas Physiomesh was substantially distorted (0.45 average).

\section{Histology}

Representative low and high magnification histology images for each of the test samples at each time point are provided in Figs. 2, 3.

\section{Inflammation}

Inflammation at 4 weeks was mild-to-moderate (score 2-3) across all groups (Fig. 4a). Among implants at 24 weeks, inflammation was minimal (less than 1) with OviTex $1 \mathrm{~S}$ Resorbable and Strattice Firm, mild with OviTex 1S Permanent, and mild-moderate for the synthetic meshes Phasix, Physiomesh, and Ventralight ST.

Biologics and reinforced biologics were initially infiltrated primarily by lymphocytes and macrophages, and in the case of reinforced biologics, neutrophils (Fig. 4b-d). At 12 and 24 weeks, macrophage infiltrate decreased to near 


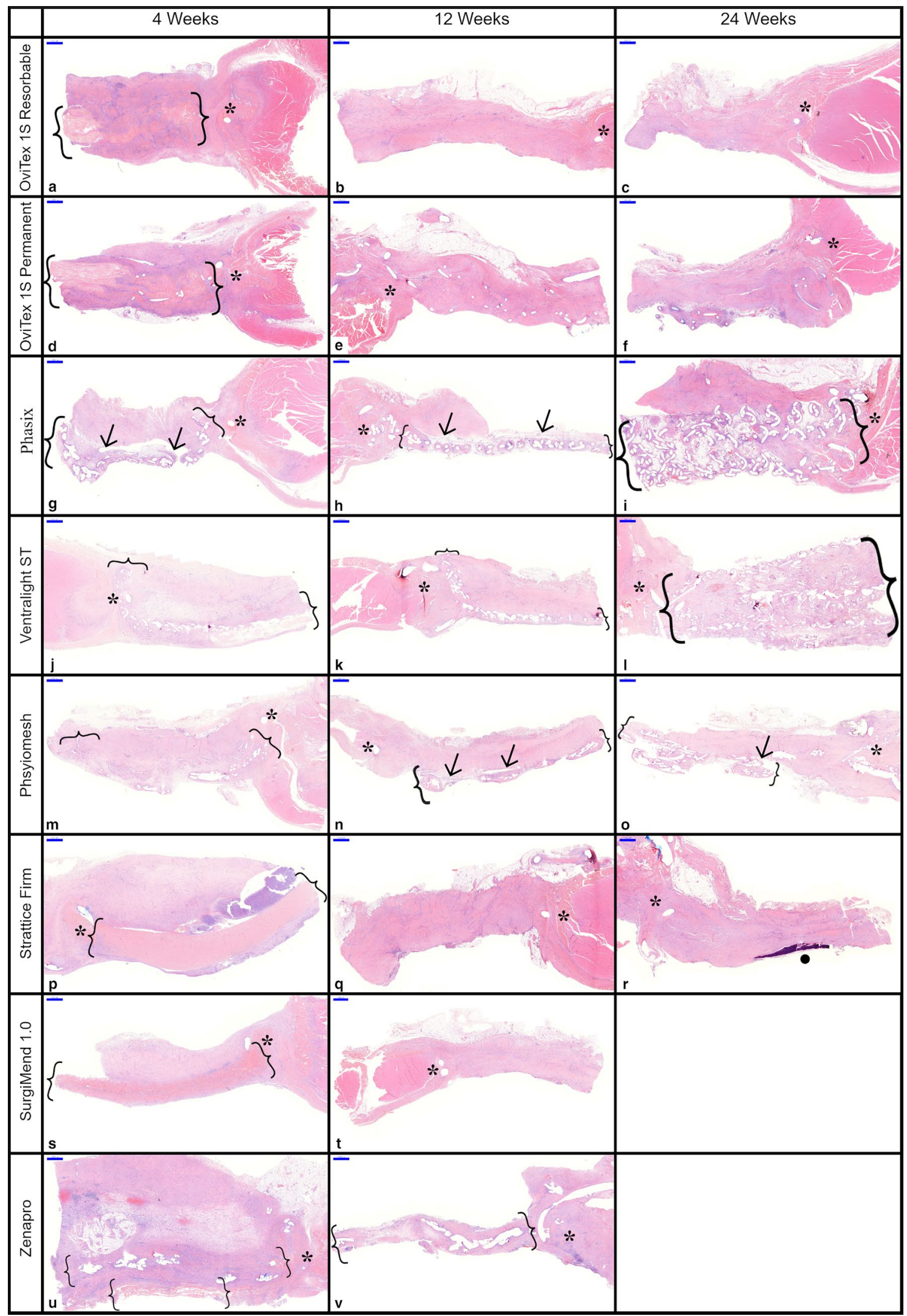

Fig. 2 Low magnification histology of all implants at 4, 12, and 24 weeks. Brackets $=$ implant material, asterisk =implant to ab wall anchoring suture, arrows $=$ delamination, and dot $=$ calcification/osseous metaplasia. Scale bar $1000 \mu \mathrm{m}$ 


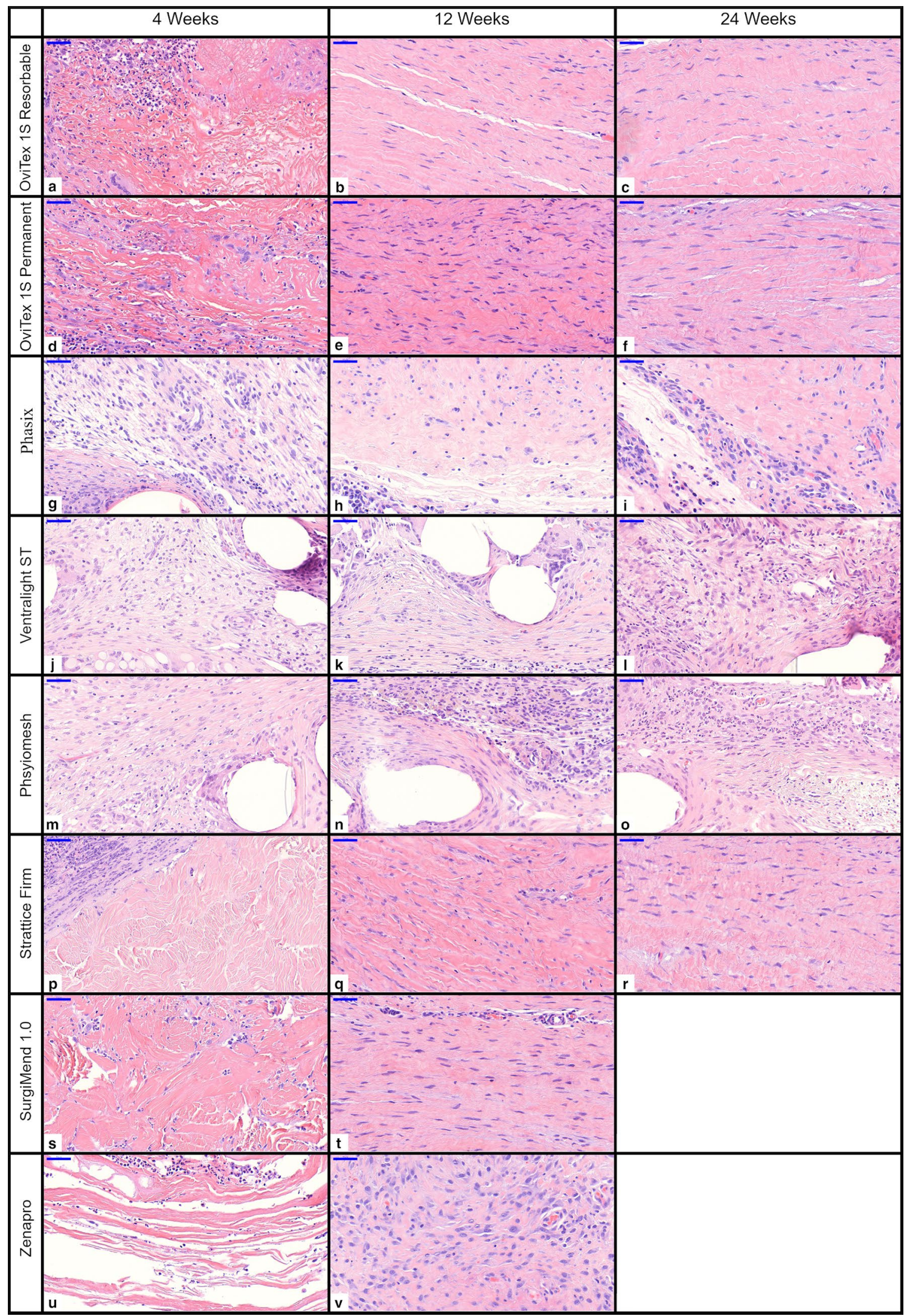

Fig. 3 High magnification histology of all implants 4, 12, and 24 weeks, scale bar $50 \mu \mathrm{m}$ 


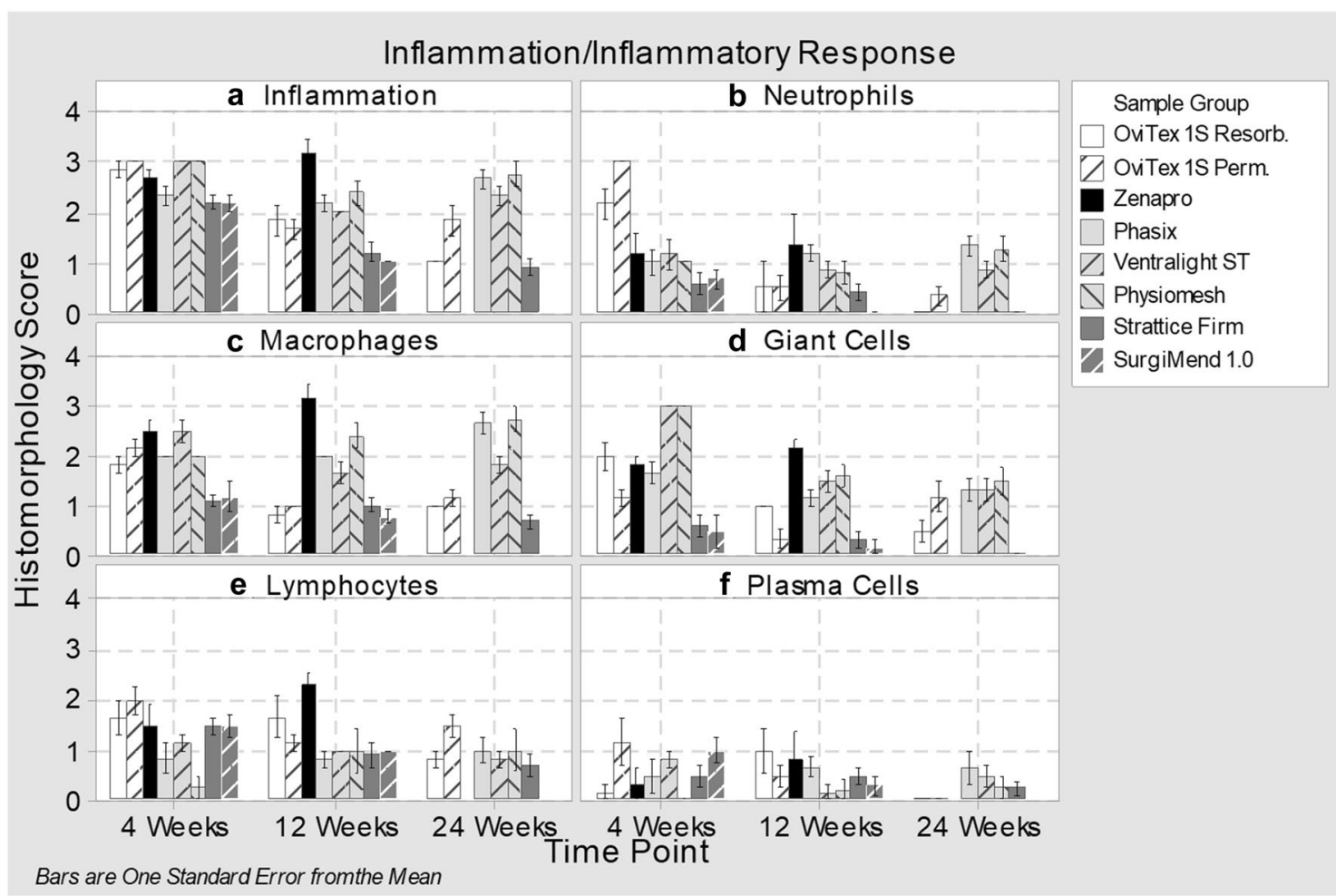

Fig. 4 Histomorphological scoring for inflammation/inflammatory response to implants at 4, 12, and 24 weeks

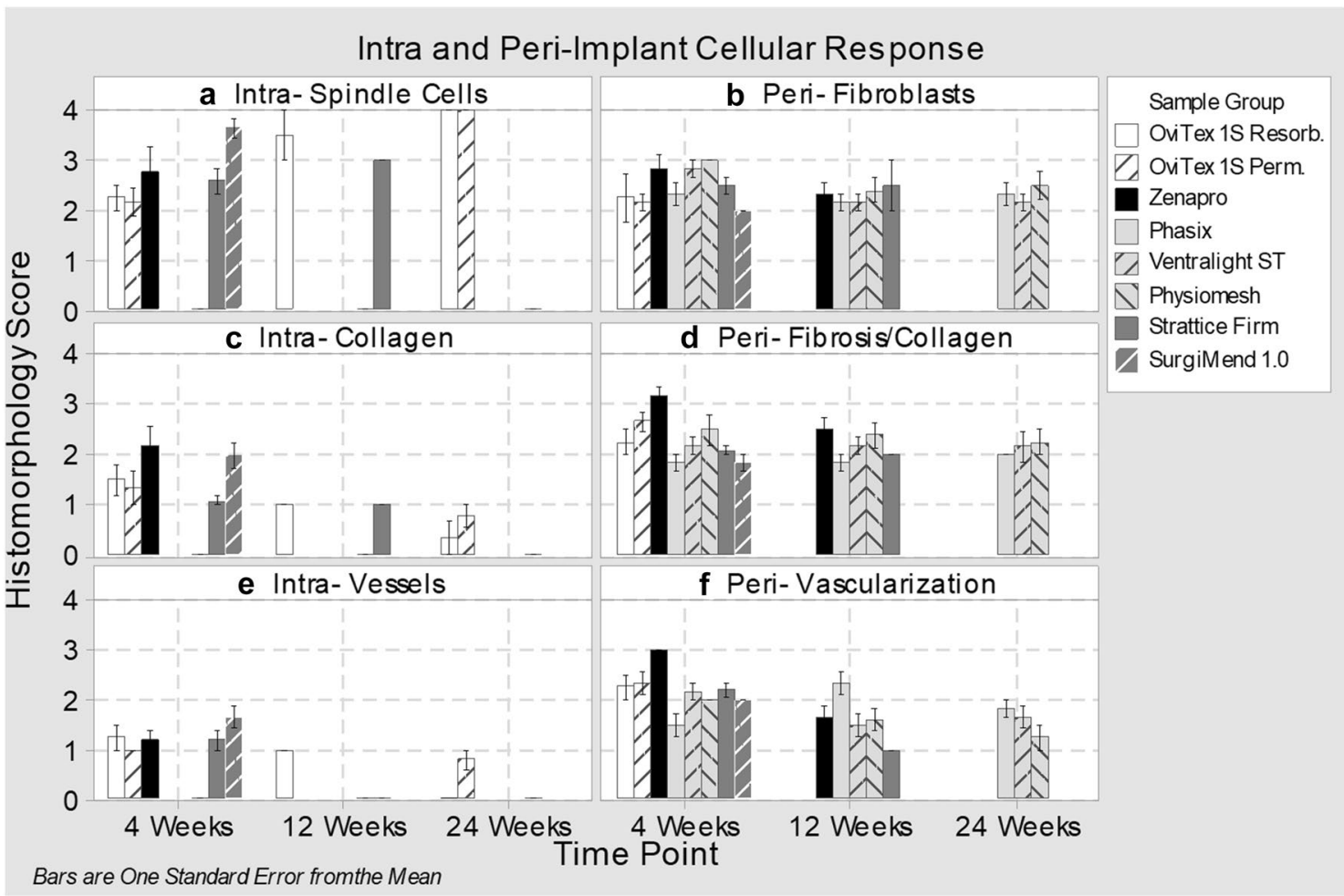

Fig. 5 Histomorphological scoring for intra- and peri-implant cellular response to implants at 4, 12, and 24 weeks 


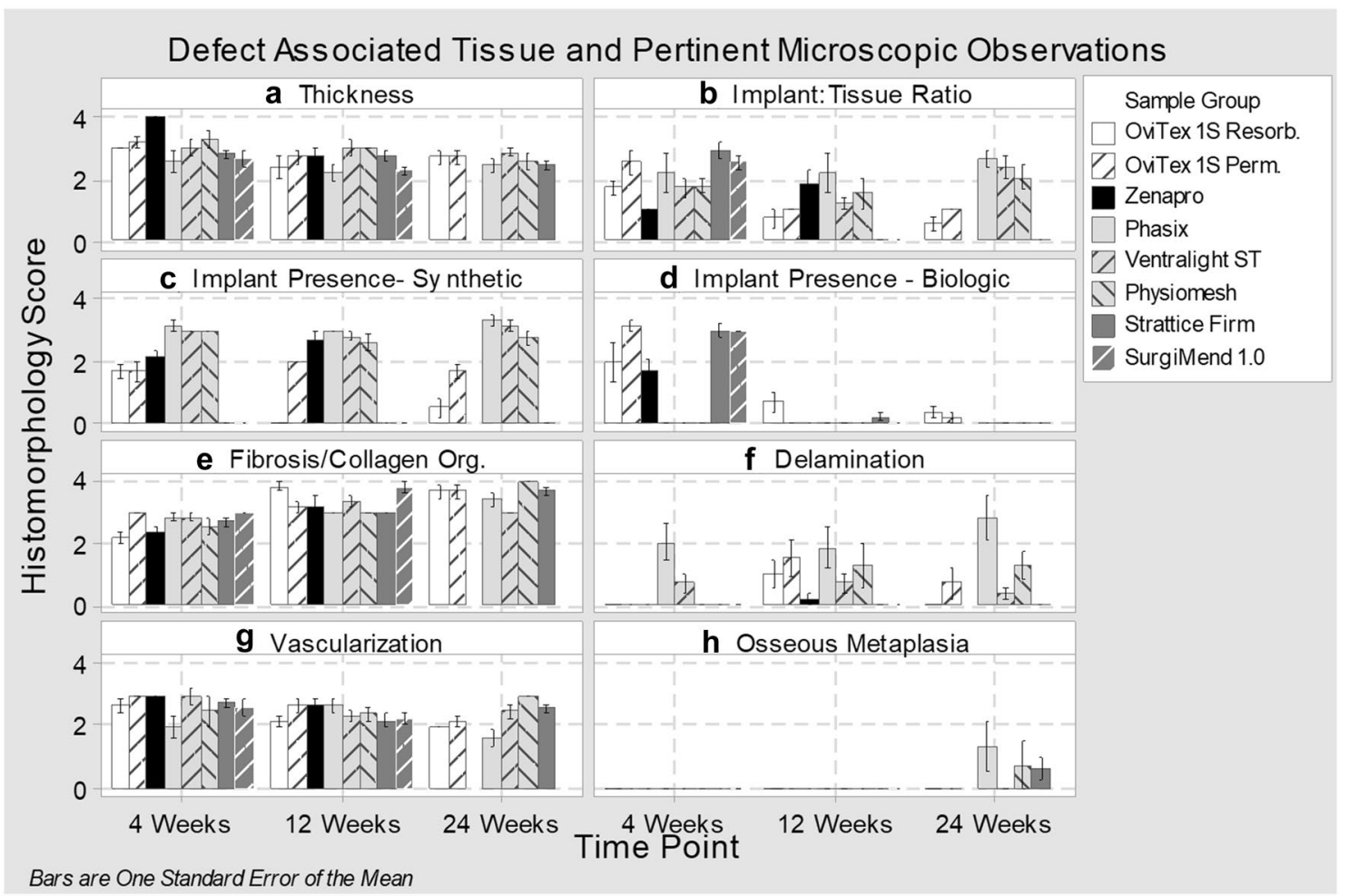

Fig. 6 Histomorphological scoring for defect-associated tissue and pertinent microscopic observations at 4, 12, and 24 weeks

minimal and near absent, respectively, as the implants were integrated into host tissue. Synthetic devices were primarily infiltrated by histiocytic cells, with giant cells and macrophages in the areas immediately surrounding the synthetic materials. The inflammatory response to these devices persisted at elevated levels throughout the study (Fig. 4a).

\section{Host cellular infiltration and fibroproliferative remodeling: biologics and reinforced biologics}

Implants containing biologic materials were evaluated for the degree and timing by which they were infiltrated by host tissue such as fibroblasts and collagen, and for the formation of vasculature. At 4 weeks, infiltration by spindle cells was mild-to-moderate (score 2-3) with both OviTex implants, Strattice Firm and Zenapro, while extensive with SurgiMend 1.0 (Figs. 3a, d, p, s, 5a). Collagen deposition and blood vessel infiltration were minimal-to-mild with all groups (score 1-2). OviTex 1S Resorbable at 12 weeks and all other biologic containing implants had diffuse tissue infiltration throughout the interstitium between individual collagen bundles at 12 or 24 weeks (Fig. 5a, c, e). This evaluation was not able to be performed for knit meshes (Phasix, Ventralight ST, and Physiomesh), because they lacked an implant interstitium. This evaluation was also not possible for the biologics after they had remodeled into host tissue.

Implant-to-tissue ratios at 4 weeks were highest with Strattice Firm, SurgiMend 1.0, and OviTex 1S Permanent (Figs. 2p, s, d, 6b). By 12 weeks, the biologic (Strattice Firm and SurgiMend 1.0) and reinforced biologic implants (both OviTex implants) had remodeled into host tissue which occupied nearly the entire defect area (Fig. 2b, e, q, t). This finding continued at 24 weeks (note SurgiMend 1.0 was not evaluated at this time) (Fig. 6b, d). At both 12 and 24 weeks, the synthetic component of OviTex 1S Permanent was detectable, while the reinforcing component of OviTex 1S Resorbable had resorbed (Fig. 6c). This explains the slightly elevated implant-to-tissue ratio of both OviTex implants in comparison to pure biologic devices. The 24-week remodeled tissue of both OviTex implants and Strattice Firm was comparable to the thickness of the native abdominal wall tissue, with increasing organization of the collagen, consistent with maturation over time (Fig. 6a, e, g).

\section{Synthetics}

The synthetic implant components of Zenapro, Phasix, Physiomesh, and Ventralight ST were persistently 
detectable throughout the study, reflecting the abundant content and durable nature of the synthetic polymers in these implants (Figs. 2i, 1, o, 6c). Although synthetic implants could not be evaluated for the degree of infiltration, there were host cells and loose connective tissue surrounding the implant fibers; and the organization of an adjacent layer of tissue, which developed asymmetrically on the subcutaneous side of the implant, was analyzed.

Implant-to-tissue ratios among synthetic implants were quantified but confounded by the persistent presence of synthetic meshes occupying a greater portion of the defect thickness over time (Fig. 6b, c). This was further confounded in events where the thickness in relation to the abdominal wall was considerably thin. Furthermore, there were other cases where the mesh bunched up and minimal amounts of deposited collagen were present, resulting in the mesh occupying significant portions of the cross section, and, therefore, a bias in the implant-to-tissue ratio.

Delamination, longitudinal splitting, or clefting along the defect wall repair tissue was also used to qualify the defect tissue area. Delamination was primarily observed in synthetics, in which the mesh was loosely adhered or entirely split from the asymmetrically deposited layer of tissue (Figs. 2g, h, n, o, $6 \mathrm{f}$ and Supplementary Fig. 2). Delamination was persistently mild with Phasix, variable but typically mild with Physiomesh, and absent to minimal with Ventralight. Of note, the biologics and reinforced biologics did not develop an asymmetric layer of tissue.

\section{Implant tissue organization and architecture}

Organization (i.e., maturity) of collagenous/fibrous connective tissue was determined by the presence of histologic features including dense lamellar collagen, low cellularity, and predominance of quiescent (fibrocytic) compared to active (fibroblastic) spindle cell morphology (Fig. 6e). At 12 weeks, the organization of tissue spanning the abdominal wall defects was moderately amorphous for Strattice Firm and OviTex 1S Permanent, and markedly lamellar for OviTex 1S Resorbable and SurgiMend 1.0 (Fig. 3q, e, b, t). At 24 weeks, biologics and reinforced biologics had mature lamellar collagen (Fig. 3c, f, r). The tissue adjacent the synthetics was predominantly amorphous, while the area immediately surrounding the mesh fibers was predominantly loose connective tissue with some thin strands of lamellar tissue (Fig. 3i, Supplementary Fig. 2). This finding was one of the more distinct findings between the classes of materials.

Adverse implant findings were limited to mineralization and osseous metaplasia at 24 weeks which was marked/ severe in one Phasix implant (also observed at 4 and 12 weeks), moderate in one Strattice Firm implant (also observed at 12 weeks), and moderate in one Physiomesh implant (Supplementary Fig. 3). There were no implant associated cavities/pockets at 24 weeks, regardless of group.

\section{Discussion}

Using a non-human primate model, a new category of hernia repair materials was evaluated in comparison to commercially available meshes. The Old-World primate model was selected, because these primates share greater than $98 \%$ of their genes with humans, and, thus, display very similar immune and foreign body responses [15]. The Caribbean Green Vervet monkey has been used extensively to evaluate clinical and immune responses to pathogens, vaccines, and pharmaceuticals, and to predict xenograft biocompatibility for abdominal wall repair $[13,17,18]$.

\section{Materials/properties (source material, ECM, and polymer content)}

The implantation of foreign materials stimulates an inflammatory response by the host. Specific characteristics of repair materials used in reconstructive surgery have been linked to different response pathways and help to determine whether the material becomes incorporated into host tissue, encapsulated by scar, or resorbed. For example, certain synthetic repair materials are associated with a potent pro-inflammatory response that results in fibrosis, scarring, and encapsulation [19]. The response to synthetic repair materials is dominated by pro-inflammatory cell phenotypes, chronic inflammation, and increased deposition of scar tissue [20]. The degree of inflammation and foreign body response differs by type of synthetic, and is generally lowest with the lighter weight polypropylene materials and greatest with microporous or heavyweight and polyester materials [20-22].

By contrast, non-crosslinked biologic repair materials that are appropriately decellularized are generally associated with limited foreign body response, reduced chronic inflammation, ingrowth of native tissue, and stimulated implant remodeling [23]. The key differentiator between synthetic and biologic materials is the presence of ECM, which is highly complex and contains a wide variety of bioactive components [8]. These components have demonstrated biological activity, including promotion of angiogenesis, cell adhesion, proliferation, differentiation, and apoptosis; and antimicrobial and chemotactic effects [9].

OviTex test articles were constructed of ECM derived from ovine forestomach (OFM), processed to retain its native structure and tissue ECM components. 
Characterization of this material has shown the retention of 153 unique matrisome proteins, including 25 collagens, 58 glycoproteins, 12 proteoglycans, 13 ECM affiliated proteins, 20 ECM regulators, and 23 secreted factors [24].

Under normal circumstances, tissue ECM and neighboring cells participate in a continuous feedback, termed 'dynamic reciprocity'. ECM influences the phenotype and behavior of nearby cells, which in turn remodel the ECM through coordinated degradation and creation of a new matrix [9]. Just like tissue ECM, dECM-based implants function in an identical manner. Initial degradation of biologic repair materials by host cells creates bioactive breakdown products and exposes additional components within the ECM, such as growth factors, that further modulate the host response. This dynamic interaction between host cells and the prosthesis promotes integration of biologic repair material into host tissue.

In this study, the observed limited foreign body response, infiltration by host cells and remodeling, confirmed the benefits of ECM. In comparison to synthetic materials, the reinforced biologics differed with respect to levels of inflammation, specifically the reduction of histiocytic cells. It is believed that the lower quantity of histiocytic cells in OviTex is due not only to the specific ECM, but also to the design and reduced areal density of synthetic materials. Phasix is a mesh with areal density of $182 \mathrm{~g} / \mathrm{m}^{2}$, which is almost twice that of Marlex $\left(95 \mathrm{~g} / \mathrm{m}^{2}\right)$, Ventralight ST a mesh at $64 \mathrm{~g} / \mathrm{m}^{2}$, and Physiomesh a mesh at $30 \mathrm{~g} / \mathrm{m}^{2}$ [25-28]. By comparison, OviTex 1S Permanent only has less than a fourth the amount of polymer of the Ventralight ST lightweight mesh $(15 \mathrm{~g} /$ $\mathrm{m}^{2}$ ), and the polymer is embedded in the ECM, which further attenuates any inflammatory response [29]. The observations show that the minimized amount of embedded synthetic reinforcement results in an implant that histologically behaves like a biologic yet maintains its functional structure (i.e., does not stretch).

\section{Macroscopic architecture and cellular infiltration: channels/pores and permeability}

OviTex was purposefully engineered and consists of layers of $\mathrm{dECM}$ with channels and pores to promote fluid exchange and allow host cells to penetrate the ECM. Fluid permeability characteristics were optimized and measured. Fluid permeability of OviTex is on average $5 \mathrm{~mL} / \mathrm{cm}^{2} / \mathrm{min}$ as compared to the acellular dermal matrices (ADM) (Strattice Firm and SurgiMend 1.0), which were measured to be essentially impermeable (e.g., $0 \mathrm{~mL} / \mathrm{cm}^{2} / \mathrm{min}$ ) (data unpublished).

At 4 weeks, the OviTex implants had host cells between and within the layers of the implant-this was not seen in Strattice Firm which histologically presented as a dense monoblock of ADM, minimally infiltrated by host cells and covered with a thin superficial layer of fibroblasts. Even though, by 12 weeks, the biologics were infiltrated and were remodeling into host collagen, the early infiltration seen with OviTex "jump started" the transition from implant into integrated host tissue. The earlier infiltration of cells and establishment of a functional vasculature may also reduce the potential for bacterial colonization and, thus, the risk for infection [30].

\section{Resultant collagen organization}

The structure and characteristics of the OviTex products led to more mature and abundant collagen spanning the entire defect area. At 12 weeks, the collagen of OviTex 1S Resorbable was described as lamellar, which matured to a higher degree of organization earlier than the synthetic and, on average, the biologic implants. By 24 weeks, both OviTex implants were remodeled into fully mature tissue. The wavy pattern of dense crimped collagen observed in OviTex is reminiscent of fascia as opposed to the random and amorphous fiber orientation typical of scar. The other biologics also exhibited this trend of increased maturity, notably for SurgiMend 1.0 at 12 weeks and Strattice Firm at 24 weeks. The organization of the collagen adjacent to synthetic meshes was more reminiscent of scar-amorphous, delayed, unorganized, and separated from the mesh by layer of loose connective tissue. No organized collagen was seen within the knitted structure of synthetic meshes.

\section{Limitations}

The predominant limitation of this study is that the model is not per se a biomechanical model of human ventral hernia repair. Although this model does not provide information regarding hernia-related outcomes such as recurrence, the model is effective in allowing for a comparison of a multitude of competitive products in human-equivalent mesh sizes and displays immune/biologic/histologic responses equivalent to those seen in humans. Another limitation was caused by the difficulty in obtaining sufficient supply of some competitive materials, which limited the number of animals that could be studied for certain groups (i.e., SurgiMend 1.0 and Zenapro). Based on the reports in the articles by Sandor 2008 and $\mathrm{Xu}$ 2008 , it was concluded that the appearance of the implants at the 4-week time point was markedly different from that at the 12 and 24 week time points, which were quite similar in appearance. We, therefore, chose 4 and 12 weeks as the time points to study for these products. Furthermore, this model uses healthy animals. As a result, the quality of the newly formed tissue observed with the materials in this study may differ from the quality of newly formed tissue in patients with various connective tissue disorders. 


\section{Conclusions}

The current study shows a favorable response to the reinforced biologics, embroidered with either polypropylene or polyglycolic acid. The test articles were associated with an initial inflammatory response, followed by resolution of inflammation and positive remodeling. By 12 weeks, the test articles were well integrated into host tissues, with little-tono non-remodeled biologic material remaining. Slight differences in outcomes between OviTex 1S Resorbable versus the OviTex 1S Permanent are due to the minimal inflammatory response to the PP reinforcement, but this did not affect the quality of the final remodeled tissue.

The results also show hernia mesh class differences, and some differences between biologics and reinforced biologics. Synthetic meshes, including the resorbable Phasix, led to an amorphous separated layer of collagen. Biologics and reinforced biologics were more often associated with lamellar collagen, which, in the case of reinforced biologics, generated more rapidly. While these initial in vivo results for the use of reinforced biologics in hernia repair are encouraging, additional clinical validation of the design is on-going via controlled clinical studies out to 24 months [31].

\section{Compliance with ethical standards}

Conflict of interest Neal Overbeck reports personal fees from TELA Bio, outside the submitted work. Gina M. Nagvajara reports personal fees from TELA Bio, outside the submitted work. Stephen Ferzoco reports other from TelaBio, outside the submitted work; and Consultant for TELA Bio. Barnaby C. H. May reports other from Aroa Biosurgery Limited (New Zealand) during the conduct of the study and outside the submitted work. In addition, Dr. May has a patent tissue scaffolds derived from forestomach extracellular matrix, US8758781B2 issued, and a patent Laminated tissue graft product, US20170360544A1 issued. Amy Beierschmitt has nothing to disclose. Shijie Qi has nothing to disclose.

Ethical approval The article complies with all international and national guidelines for the care of animals. The protocol for this study was reviewed and approved by the BSF Institutional Animal Care and Use Committee (IACUC).

Human and animal rights All animals were treated in accordance with the Guide for the Care and Use of Laboratory Animals (as outlined in NIH Publication \#85-23 Rev. 1985). This article does not contain any studies with human participants.

Informed consent Informed consent was not required for this type of study.

Open Access This article is licensed under a Creative Commons Attribution 4.0 International License, which permits use, sharing, adaptation, distribution and reproduction in any medium or format, as long as you give appropriate credit to the original author(s) and the source, provide a link to the Creative Commons licence, and indicate if changes were made. The images or other third party material in this article are included in the article's Creative Commons licence, unless indicated otherwise in a credit line to the material. If material is not included in the article's Creative Commons licence and your intended use is not permitted by statutory regulation or exceeds the permitted use, you will need to obtain permission directly from the copyright holder. To view a copy of this licence, visit http://creativecommons.org/licenses/by/4.0/.

\section{References}

1. Burger JWA, Luijendijk RW, Hop WCJ, Halm JA, Verdaasdonk EGG, Jeekel J (2004) Long-term follow-up of a randomized controlled trial of suture versus mesh repair of incisional hernia. Trans Meet Am Surg Assoc CXXII. https://doi.org/10.1097/01. sla.0000141193.08524.e7

2. Kokotovic D, Bisgaard T, Helgstrand F (2016) Long-term recurrence and complications associated with elective incisional hernia repair. JAMA 316(15):1575-1582. https://doi.org/10.1001/ jama.2016.15217

3. Luijendijk RW, Hop WC, van den Tol MP, de Lange DC, Braaksma MM, Ijermans JN, Boelhouwer RU, de Vries BC, Salu MK, Wereldsma JC, Bruijninckx CM, Jeekel J (2000) A comparison of suture repair with mesh repair for incisional hernia. N Engl J Med 343(6):392-398. https://doi.org/10.1056/NEJM2 00008103430603

4. Cozad MJ, Grant DA, Bachman SL, Grant DN, Ramshaw BJ, Grant SA (2010) Materials characterization of explanted polypropylene, polyethylene terephthalate, and expanded polytetrafluoroethylene composites: spectral and thermal analysis. J Biomed Mater Res B Appl Biomater 94(2):455-462. https://doi. org/10.1002/jbm.b.31675

5. Rosen MJ, Bauer JJ, Harmaty M, Carbonell AM, Cobb WS, Matthews B, Goldblatt MI, Selzer DJ, Poulose BK, Hansson BM, Rosman C, Chao JJ, Jacobsen GR (2017) Multicenter, prospective, longitudinal study of the recurrence, surgical site infection, and quality of life after contaminated ventral hernia repair using biosynthetic absorbable mesh: the COBRA study. Ann Surg 265(1):205-211. https://doi.org/10.1097/SLA.0000000000001601

6. Roth JS, Anthone GJ, Selzer DJ, Poulose BK, Bittner JG, Hope WW, Dunn RM, Martindale RG, Goldblatt MI, Earle DB, Romanelli JR, Mancini GJ, Greenberg JA, Linn JG, Parra-Davila E, Sandler BJ, Voeller GR (2019) Prospective evaluation of poly4-hydroxybutyrate mesh in CDC class I, high-risk ventral and incisional hernia repair: 3-year follow-up. Poster presented at: SAGES 2017 annual meeting; 2017 March 22-25; Houston, TX

7. Garvey PB, Giordano SA, Baumann DP, Liu J, Butler CE (2017) Long-term outcomes after abdominal wall reconstruction with acellular dermal matrix. J Am Coll Surg 224(3):341-350. https:// doi.org/10.1016/j.jamcollsurg.2016.11.017

8. Hynes RO, Naba A (2012) Overview of the matrisome-an inventory of extracellular matrix constituents and functions. Cold Spring Harb Perspect Biol 4(1):a004903. https://doi.org/10.1101/ cshperspect.a004903

9. Brown BN, Badylak SF (2014) Extracellular matrix as an inductive scaffold for functional tissue reconstruction. Transl Res 163(4):268-285. https://doi.org/10.1016/j.trsl.2013.11.003

10. Butler CE, Prieto VG (2004) Reduction of adhesions with composite AlloDerm/polypropylene mesh implants for abdominal wall reconstruction. Plast Reconstr Surg 114(2):464-473. https://doi. org/10.1097/01.Prs.0000132670.81794.7e

11. FitzGerald JF, Kumar AS (2014) Biologic versus synthetic mesh reinforcement: what are the pros and cons? Clin Colon Rectal Surg 27(4):140-148. https://doi.org/10.1055/s-0034-1394155 
12. Annor AH, Tang ME, Pui CL, Ebersole GC, Frisella MM, Matthews BD, Deeken CR (2012) Effect of enzymatic degradation on the mechanical properties of biological scaffold materials. Surg Endosc 26(10):2767-2778. https://doi.org/10.1007/s0046 4-012-2277-5

13. Xu H, Wan H, Sandor M, Qi S, Ervin F, Harper JR, Silverman RP, McQuillan DJ (2008) Host response to human acellular dermal matrix transplantation in a primate model of abdominal wall repair. Tissue Eng Part A 14(12):2009-2019. https://doi. org/10.1089/ten.tea.2007.0316

14. Sandor M, Xu H, Connor J, Lombardi J, Harper JR, Silverman RP, McQuillan DJ (2008) Host response to implanted porcine-derived biologic materials in a primate model of abdominal wall repair. Tissue Eng Part A 14(12):2021-2031. https://doi.org/10.1089/ten. tea. 2007.0317

15. Qi S, Xu D, Ma A, Zhang X, Chida N, Sudo Y, Tamura K, Daloze P, Chen H (2006) Effect of a novel inducible nitric oxide synthase inhibitor, FR260330, in prevention of renal ischemia/reperfusion injury in vervet monkeys. Transplantation 81(4):627-631. https ://doi.org/10.1097/01.tp.0000199282.05021.0c

16. Zhang J, Wang GY, Xiao YP, Fan LY, Wang Q (2011) The biomechanical behavior and host response to porcine-derived small intestine submucosa, pericardium and dermal matrix acellular grafts in a rat abdominal defect model. Biomaterials 32(29):70867095. https://doi.org/10.1016/j.biomaterials.2011.06.016

17. Lemere CA, Beierschmitt A, Iglesias M, Spooner ET, Bloom JK, Leverone JF, Zheng JB, Seabrook TJ, Louard D, Li D, Selkoe DJ, Palmour RM, Ervin FR (2004) Alzheimer's disease abeta vaccine reduces central nervous system abeta levels in a non-human primate, the Caribbean vervet. Am J Pathol 165(1):283-297. https ://doi.org/10.1016/s0002-9440(10)63296-8

18. Ouwe-Missi-Oukem-Boyer O, Mezui-Me-Ndong J, Boda C, Lamine I, Labrousse F, Bisser S, Bouteille B (2006) The vervet monkey (Chlorocebus aethiops) as an experimental model for Trypanosoma brucei gambiense human African trypanosomiasis: a clinical, biological and pathological study. Trans R Soc Trop Med Hyg 100(5):427-436. https://doi.org/10.1016/j.trstm h.2005.07.023

19. Vogels RR, van Barneveld KW, Bosmans JW, Beets G, Gijbels MJ, Schreinemacher MH, Bouvy ND (2015) Long-term evaluation of adhesion formation and foreign body response to three new meshes. Surg Endosc 29(8):2251-2259. https://doi.org/10.1007/ s00464-014-3936-5

20. Orenstein SB, Saberski ER, Kreutzer DL, Novitsky YW (2012) Comparative analysis of histopathologic effects of synthetic meshes based on material, weight, and pore size in mice. J Surg Res 176(2):423-429. https://doi.org/10.1016/j.jss.2011.09.031

21. Cobb WS, Kercher KW, Heniford BT (2005) The argument for lightweight polypropylene mesh in hernia repair. Surg Innov 12(1):63-69. https://doi.org/10.1177/155335060501200109
22. Klinge U, Klosterhalfen B, Birkenhauer V, Junge K, Conze J, Schumpelick V (2002) Impact of polymer pore size on the interface scar formation in a rat model. J Surg Res 103(2):208-214. https://doi.org/10.1006/jsre.2002.6358

23. Bryan N, Ahswin H, Smart N, Bayon Y, Wohlert S, Hunt JA (2014) The in vivo evaluation of tissue-based biomaterials in a rat full-thickness abdominal wall defect model. J Biomed Mater Res B Appl Biomater 102(4):709-720. https://doi.org/10.1002/ jbm.b. 33050

24. Dempsey SG, Miller CH, Hill RC, Hansen KC, May BCH (2019) Functional insights from the proteomic inventory of ovine forestomach matrix. J Proteome Res 18(4):1657-1668. https://doi. org/10.1021/acs.jproteome.8b00908

25. Martin DP, Badhwar A, Shah DV, Rizk S, Eldridge SN, Gagne DH, Ganatra A, Darois RE, Williams SF, Tai HC, Scott JR (2013) Characterization of poly-4-hydroxybutyrate mesh for hernia repair applications. J Surg Res 184(2):766-773. https://doi. org/10.1016/j.jss.2013.03.044

26. Ethicon J\&J Medical Devices (2019) https://www.jnjmedicaldevic es.com/en-US/companies/ethicon. Accessed 12 Aug 2019

27. Bard Davol Inc (2015) Ventralight ST Mesh Product Brochure. DAV/VLST/0814/0006(2)

28. Cobb WS, Burns JM, Peindl RD, Carbonell AM, Matthews BD, Kercher KW, Heniford BT (2006) Textile analysis of heavy weight, mid-weight, and light weight polypropylene mesh in a porcine ventral hernia model. J Surg Res 136(1):1-7. https://doi. org/10.1016/j.jss.2006.05.022

29. Liang R, Knight K, Barone W, Powers RW, Nolfi A, Palcsey S, Abramowitch S, Moalli PA (2017) Extracellular matrix regenerative graft attenuates the negative impact of polypropylene prolapse mesh on vagina in rhesus macaque. Am J Obstet Gynecol 216(2):153 e151-153 e159. https://doi.org/10.1016/j. ajog.2016.09.073

30. Agyingi E, Maggelakis S, Ross D (2010) The effect of bacteria on epidermal wound healing. Math Model Nat Phenom 5(3):28-39

31. DeNoto G et al (2019) Reinforced biologic reduces risk of recurrence in ventral hernia (vh) patients: one-year data from the bravo ventral hernia study. In: Presented at 11th annual abdominal wall reconstruction 2019 conference, June 6-8, 2019, Washington, DC

Publisher's Note Springer Nature remains neutral with regard to jurisdictional claims in published maps and institutional affiliations. 